\title{
POLITICA ENERGETICĂ A FEDERAȚIEI RUSE, INSTRUMENT DE AFIRMARE A STATUTULUI DE MARE PUTERE
}

\author{
THE RUSSIAN FEDERATION ENERGY POLICY, \\ AN INSTRUMENT FOR RECONSOLIDATING THE STATUS \\ OF HIGH POWER
}

\author{
Lt.col.conf.univ.dr. Andi Mihail BĂNCILĂ*
}

\begin{abstract}
Dezintegrarea URSS, produsă în decembrie 1991, a marcat, din punct de vedere istoric, finalul Războiului Rece. Foarte mulți dintre analiștii de politică externă s-au grăbit să afirme că Federația Rusă a încetat să mai reprezinte o amenințare pentru lumea occidentală. În ciuda faptului că s-a confruntat cu o multitudine de probleme economice, sociale şi militare, sub conducerea lui Vladimir Putin, statul rus a reuşit să renască. Revenirea miraculoasă a Federației Ruse a fost posibilă ca urmare a implementării cu succes a unei politici de centralizare economică, ce s-a suprapus cu o perioadă de creștere, la nivel global, a prețurilor la hidrocarburi. Prosperitatea economică a încurajat guvernul rus să revină la vechile practici din perioada sovietică, reușind să dezechilibreze fragilele state din Europa de Est și să pună din nou în pericol pacea întregului continent.

The disintegration of the USSR in December 1991 marked the end of the Cold War. Many foreign policy analysts were quick to point out that Russian Federation had ceased to be a threat to the Western world. Despite facing a multitude of economic, social and military problems, under the leadership of Vladimir Putin the Russian state managed to be reborn. Russian Federation's miraculous return was made possible by the successful implementation of a policy of economic centralization that overlapped with a period of rising global oil prices. Economic prosperity encouraged the Russian Federation government to return to the old practices of the Soviet period, succeeding in unbalancing the fragile states of Eastern Europe and once again endangering the peace of the entire continent.
\end{abstract}

Cuvinte-cheie: Federația Rusă; Războiul Rece; Crimeea; hidrocarburi; conflict.

Keywords: Russian Federation; Cold War; Crimea; hydrocarbons; conflict.

Chiar dacă, spre finalul secolului XX, majoritatea oamenilor politici și a celor din spațiul universitar vedeau Federația Rusă ca pe o fostă mare putere, incapabilă să-şi mai onoreze angajamentele la scară globală, începutul secolului al XXI-lea ne oferă o imagine cu mult diferită faţă de percepția iniţială. Pentru a înțelege care este poziția pe care o ocupă Federația Rusă într-o lume de tip multipolar și care va fi evoluția sa în prima jumătate a secolului al XXI-lea, trebuie să privim cu mare atenție drumul pe care l-a parcurs în ultimii 500 de ani. Interesant de subliniat este faptul că evoluția sinuoasă a statului rus pune în dificultate specialiștii, care încearcă să anticipeze viitorul acestuia. În tot acest interval

\footnotetext{
*Academia Tehnică Militară „Ferdinand I” e-mail: bancila.andi@gmail.com
}

de timp, statul rus s-a comportat atipic, în raport cu experienţa oricărei alte mari puteri, reușind ca, după fiecare situație limită prin care a trecut, să fie capabil să renască.

\section{Moștenirea sovietică}

Odată cu desființarea fostului Imperiu Sovietic, Federația Rusă a devenit moștenitoarea firească a celor mai importante elemente din patrimoniul acestuia (armele nucleare și locul în Consiliul de Securitate al $\mathrm{ONU}^{1}$ ). Imensul arsenal nuclear desfășurat în perioada Războiului Rece atât pe teritoriul sovietic, cât și pe cel al unora dintre statele din estul Europei a fost retras, conform unor importante acorduri internaționale, pe teritoriul rus². Într-o primă fază a desfășurării acestui proces, au existat numeroase tratative între Federația Rusă și fostele republici, Ucraina, 
Kazahstan și Belarus, care doreau conservarea, pe teritoriul lor, a unei părţi din acest arsenal. Conștientizând riscul proliferării nucleare, SUA au susținut retragerea totală a acestor arme în Rusia, și prin Memorandumul, semnat la Budapesta, pe 5 decembrie $1994^{3}$, au garantat fostelor republici sovietice integritatea teritorială, precum și sprijin, în cazul încălcării acestei înțelegeri ${ }^{4}$.

Din punct de vedere economic, Federaţia Rusă a rămas principala putere a fostului imperiu sovietic, deținând direct sau indirect accesul la majoritatea resurselor minerale. Pe toată durata anilor '90, statul rus a ocupat primul loc în lume la producția de gaze naturale și locul opt la producția de petrol $^{5}$, poziție pe care o consolida prin controlul livrărilor acestor resurse, extrase din statele Asiei Centrale (conductele de petrol și gaze care deserveau zăcămintele acestor state erau interconectate doar cu cele rusești, neexistând o altă variantă pentru exportul lor). Chiar dacă rolul cărbunelui se diminuase în funcționarea noilor capacități industriale, din punct de vedere energetic, el a continuat să joace un rol esențial. Federația Rusă deținea a doua rezervă mondială de cărbune, care, alături de potențialul său hidroenergetic, transforma acest stat în al patrulea producător de energie electrică al planetei ${ }^{6}$. Cu ajutorul companiei Gazprom, care exploata 94\% din resursele de gaze naturale ale țării ${ }^{7}$ și care deținea pachete importante de acțiuni ale unor companii europene, Federația Rusă a reușit să pună în dificultate statele europene ori de câte ori interesele sale geopolitice au cerut-o. Întreruperea livrărilor de gaze naturale în perioada iernii sau chiar stoparea totală a exporturilor către unele state a devenit o practică curentă. În acest mod, Federația Rusă a reușit să obțină numeroase concesii economice sau chiar politice. Foarte puține dintre statele dependente de importurile de hidrocarburi au adoptat o atitudine fermă în momentele în care liderul politic de la Kremlin a încălcat în mod voit tratatele și reglementările internaţionale în vigoare. Există chiar situații în care unii lideri europeni, precum prim-ministrul Ungariei, Victor Orban, au susținut în mod indirect anumite iniţiative rusești ${ }^{8}$.

\section{Resursele energetice, principalul atu al politicii externe ruse}

Parcursul Federației Ruse în epoca post Război Rece s-a dovedit a fi deosebit de sinuos, perioadele de normalizare, de escaladare și de criză a relațiilor sale, în raport cu ceilalţi membri ai comunităţii internaționale, variind foarte mult. După dispariţia URSS, statul rus a traversat o puternică criză politică și economică, ce i-a afectat credibilitatea internațională. După privatizările ratate din anii '90, multe fabrici și-au închis porțile, disponibilizând milioane de ruși. Singurele domenii care, teoretic, încă puteau produce profit erau companiile din sectorul energetic, care, din păcate, fuseseră acaparate de un grup de interese, cunoscut sub numele de oligarhi (foști membri marcanţi ai PCUS sau ai serviciilor secrete). Pierderile financiare majore au slăbit conducerea centralizată și au permis acestor ,investitori” să guverneze regiunile în care își desfăşurau activitatea, sfidând, în unele cazuri, conducerea de la Moscova.

Tentativa statelor europene, de a se emancipa de sub controlul energetic al Rusiei, s-a dovedit a fi deosebit de anevoioasă. La începutul anilor ' 90 , Occidentul a susţinut un proiect de liberalizare a exploatării resurselor energetice ruse ${ }^{9}$. La 12 mai 1993, prin rezoluția guvernamentală cu numărul 354 , cele două mari companii petroliere de stat, Yuganskneftegaz (producea 11\% din petrolul extras de Federația Rusă) și Kuybyshevnefteorgsintez (extrăgea 9\% din petrolul Federației Ruse), au fost unificate într-o singură companie, Yukos ${ }^{10}$, care, în anul 1996, a fost vândută lui Mihail Hodorkovski. Omul din spatele acestei afaceri a acumulat, în foarte scurt timp, o putere impresionantă, lucru care i-a permis să influenţeze foarte multe aspecte ale politicii economice a statului rus. În momentul său de glorie, Yukos producea 20\% din petrolul Federației Ruse și putea decide unde şi la ce preț își vindea producția, sabotând, în unele cazuri, deciziile politice ale guvernului rus. Această companie privată putea, din punct de vedere teoretic, să-și livreze produsele pe piețele occidentale, fără a răspunde ordinelor venite de la Kremlin. Conștientizând riscul care decurgea din liberalizarea pieței, noua conducere politică creată de Vladimir Putin a decis naţionalizarea acestei companii. Mișcarea de centralizare a producției energetice a debutat la 25 octombrie 2003, odată cu arestarea oligarhului rus pentru evaziune fiscală. El a fost acuzat că a delapidat statul cu mai multe miliarde de dolari, în anul 2004 averea sa personală fiind evaluată de publicația Forbes la aproximativ 15 miliarde de dolari americani ${ }^{11}$. 
Pentru a diminua pierderile înregistrate de marile companii, guvernul de la Moscova, sub conducerea noului lider Vladimir Putin, a naționalizat sau și-a crescut participația la multe dintre marile companii energetice ale țării. Acest lucru, cumulat cu o perioadă de creștere a prețurilor la hidrocarburi, a permis Rusiei să-și reconsidere poziția avută la masa marilor puteri și să revină în forță pentru a redobândi o parte a fostului spațiu de influenţă. Chiar dacă, iniţial, analiștii politici și economici au avut dubii serioase cu privire la acceptarea Federației Ruse în clubul elitist al celor mai industrializate state ale lumii, începând cu anul 1997, ea a fost acceptată în grupul G7, devenit, începând cu acel moment, G8 ${ }^{12}$.

Reinstituirea monopolului statului rus asupra propriilor sale resurse energetice a oferit noului lider de la Kremlin, Vladimir Putin, pârghiile necesare redobândirii statutului de mare putere. Din cauza monopolului pe care îl aveau pe piaţa energetică europeană, negocierile pentru obținerea de tehnologie și fonduri suplimentare pentru noi investiţii au fost deosebit de dure. Acest lucru a obligat statele occidentale să identifice o nouă cale pentru a reduce dependența energetică de Federația Rusă $^{13}$. Oamenii politici au încercat să promoveze o serie de proiecte prin intermediul cărora ar fi redus dependența de resursele importate din Federaţia Rusă. Foarte multe fonduri au fost alocate dezvoltării sectorului energiei alternative (eolian, solar, hidroenergetic etc.). În cadrul unui ambiţios plan pe termen mediu și lung, Uniunea Europeană și-a propus ca, până în anul 2030, să reducă cu 40\% cantitatea de $\mathrm{CO}_{2}$ eliminată în atmosferă, iar până în anul 2050, procentul să crească la $60 \%{ }^{14}$.

Acest deziderat nu poate produce efecte imediate, motiv pentru care statele europene au nevoie să elaboreze și alte strategii energetice. În acest sens, ele au aprobat alocarea de fonduri și pentru realizarea unor terminale destinate importurilor de gaze naturale lichefiate, pe care intenţionau să le utilizeze în scopul importării de gaze din Norvegia, din Qatar și de gaze de șist, extrase din SUA $^{15}$. Proiectul cel mai accesibil și cu randamentul cel mai mare, realizabil într-o perioadă scurtă de timp, era construcția unui sistem de conducte concurente cu cele ale Federaţiei Ruse, prin intermediul cărora s-ar fi putut importa gaze naturale ieftine din zona Asiei Centrale. Constructia proiectului Nabucco, care ar fi trebuit să livreze Europei gaz ieftin din Marea Caspică ${ }^{16}$, a devenit prioritatea zero a UE și s-au comandat o serie de studii de impact. Gazoductul, lung de 3.900 de kilometri, urma să fie un proiect comun al Turciei, Bulgariei, României, Ungariei și Austriei, care, prin companiile naționale, ar fi trebuit să controleze un procent din viitoarea afacere ${ }^{17}$. Azerbaidjanul, Turkmenistanul și Kazahstanul ar fi trebuit să devină furnizori importanți ai statelor europene, care ar fi putut, astfel, să beneficieze de gaze naturale la prețuri competitive.

Din păcate, acest demers a fost cu ușurință anulat de Gazprom, care a demarat construcția a douănoi proiecte concurente, North și South Stream, în care a reuşit să atragă, încă de la început, o serie de state-cheie ale proiectului Nabucco (Bulgaria și Ungaria), precum și pe cel mai important consumator european de gaze naturale, Germania. Mai mult decât atât, Federația Rusă s-a asigurat că Georgia, una dintre țările pe teritoriul căreia urma să fie construită o parte importantă a conductei, ar fi urmat să intre în faliment și chiar să își piardă suveranitatea asupra unor importante regiuni din propriul teritoriu. În acest sens, guvernanții ruși au reactivat unul dintre conflictele înghețate în anii '90 și au aruncat statul într-un interminabil război civil. În anul 2008, trupele Federaţiei Ruse au intervenit direct împotriva statului georgian, rupând din teritoriul acestuia două republici autonome, Abhazia și Osetia de $\mathrm{Sud}^{18}$, amânând astfel, pe termen nedefinit, construcția conductei.

Strategia energetică a Federației Ruse s-a dovedit a fi mult mai complexă, luând în calcul mult mai multe variante posibile. Încă din primul moment în care a adoptat decizia de a se construi un sistem de conducte care să ocolească teritoriul Ucrainei, Rusia a încercat să câștige bunăvoința unora dintre statele Uniunii Europene. Jocul geopolitic al Federație Ruse a fost susținut indirect de Germania, care a devenit principalul importator şi, ulterior, distribuitor de gaz rusesc, două companii înregistrate în acest stat au devenit parteneri ai proiectului North Stream (companiile Wintershall Holdings și E.ON Ruhrgas dețineau câte $15,5 \%$ din proiect) ${ }^{19}$. Alte state membre ale spațiului economic european și-au asumat părți din acest proiect, participând cu companiile energetice proprii la construcția gazoductului și primind beneficii importante. Olanda și Franța, reprezentate de N. V. Nederlandse Gasunie și GDF Suez S.A., 
au fost înregistrate ca parteneri ai proiectului, fiind recompensate cu câte $9 \%$ din acțiuni ${ }^{20}$.

Achizițiile strategice au permis statului rus să obțină chiar controlul indirect al viitorului proiect Nabucco, prin intermediul Gazprom, Federația Rusă a ajuns să controleze $30 \%$ din pachetul companiei austriece Baumgarten și $20 \%$ din compania Centrex Europe Energy, care urmau să fie implicate în construcția viitoarei conducte ${ }^{21}$. În cazul în care Nabucco ar putea deveni realitate, companiile rusești deja controlează direct sau indirect producția de gaze a Azerbaidjanului, achiziționând, la un preț supraevaluat, exploatarea de la Shah Deniz, cu o capacitate confirmată de 15 mld. de metri cubi anual $^{22}$. Mai mult, Federația Rusă și-a securizat și o parte importantă a traseului viitoarei conducte, încheind parteneriate strategice cu o parte dintre statele central europene. Ungaria a devenit unul dintre principalii parteneri comerciali ai statului rus din această zonă geografică, beneficiind de livrări de gaze naturale la prețuri preferențiale și de câștiguri consistente, rezultate în urma privatizării companiei petroliere de stat MOL (prin intermediul companiei Surgutneftegaz, Rusia a achiziționat, la preț dublu față de listarea la bursă, un important pachet de acțiuni al companiei maghiare ${ }^{23}$ ).

\section{Şantajul politic și intervenția militară, parte importantă a diplomației ruse}

Chiar dacă Federația Rusă a reușit să păstreze o mare parte a privilegiilor internaționale ale fostei URSS, poziția sa geopolitică s-a degradat semnificativ, în special ca urmare a pierderii unor teritorii care îi asigurau acces la oceanul planetar. Ieșirea la Marea Baltică a Federației Ruse s-a redus la un coridor cu lățimea de doar 6 mile marine ${ }^{24}$, în dreptul localității Sankt Petersburg, și la o altă mică porţiune în zona enclavei Kaliningrad, unde a fost desfăşurată cea mai mare parte a flotei din Baltica (se pierduseră zonele litorale adiacente fostelor republici Lituania, Letonia și Estonia, iar Finlanda solicitase creșterea limitelor apelor teritoriale, de la 4 la 12 mile marine). De asemenea, Federaţia Rusă a pierdut, în favoarea Ucrainei și Georgiei, cea mai mare parte a ieșirii la Marea Neagră, inclusiv Peninsula Crimeea, care fusese transferată de către secretarul general al PCUS Nikita Hrușciov (ucrainean de origine), în anul 1954, Republicii Sovietice Socialiste Ucraina ${ }^{25}$. Flota de la Marea Neagră fusese împărțită între cele trei state succesoare ale URSS, Rusia adjudecându-și aproape $70 \%$ dintre nave. Pentru că cea mai mare parte a infrastructurii portuare era amplasată în Crimeea, la Sevastopol, cele două state au semnat un tratat care permitea marinei ruse să staţioneze în acest port până în anul 201726. Profitând de instalarea în fotoliul prezidențial de la Kiev a prorusului Victor Ianukovici, în anul 2010 Federația Rusă a renegociat acordul, obținând o prelungire a staționării trupelor ruse în peninsulă pentru încă 25 de ani.

Problema staționării marinei ruse în Sevastopol se rediscută după răsturnarea de la putere a președintelui prorus Viktor Ianukovici și instalarea la Kiev a unui guvern favorabil Occidentului ${ }^{27}$. Ucraina a iniţiat discuții de asociere și, ulterior, de aderare la cele două structuri euroatlantice, NATO și UE. Acest lucru a deranjat puternic conducerea de la Kremlin, care considera inacceptabilă posibilitatea de a se învecina direct pe o linie de frontieră atât de lungă $\breve{a}^{28}$ cu organizația de securitate colectivă concurentă. Răspunsul Federației Ruse nu s-a lăsat așteptat, prin vocea președintelui Putin s-a lansat ipoteza potrivit căreia frontiera a fost garantată unui alt stat, nu celui care s-a afirmat după mișcarea cunoscută sub numele de Euromaidan ${ }^{29}$.

Chiar dacă, după dezmembrarea fostei URSS, prestigiul internațional al Federației Ruse scăzuse semnificativ, majoritatea organizațiilor internaționale create și coordonate de Moscova (Tratatul de la Varșovia, CAER) intraseră în disoluție, iar statele lumii a treia care gravitau în jurul ei își căutaseră noi protectori, încet, dar sigur, Federația Rusă a reușit să se reașeze la masa marilor puteri. Eforturile redobândirii influenței politice şi economice, inclusiv în cadrul fostului imperiu sovietic au fost semnificative.

La 8 decembrie $1991^{30}$, cu puţin timp înainte de colapsul fostei URSS, conducerea de la Kremlin a înființat o nouă organizație de cooperare economică, denumită Comunitatea Statelor Independente. Cel mai probabil, sursa de inspirație fusese Commonwealth-ul britanic, care urmărise conservarea pieței unice a fostului său imperiu colonial. CSI (Comunitatea Statelor Independente $)^{31}$ trebuia să joace rolul unei piețe comune pentru statele din fostul imperiu sovietic. La această organizație, au aderat, inițial, 11 dintre cele 15 state foste membre ale URSS, cărora, în decembrie 1993, li s-a adăugat și Georgia ${ }^{32}$ 
(excepție au făcut statele baltice care începuseră negocierile pentru integrarea lor euroatlantică). La fel ca și în cazul pieței unice a fostului imperiu britanic, CSI a întâmpinat mari dificultăţi de funcționare, în special ca urmare a concurenței pe care alte mari puteri o creaseră în acest spațiu. Multe dintre întreprinderile sovietice care funcționau cu subansamble produse pe tot cuprinsul fostei URSS și-au diversificat furnizorii și, indirect, au falimentat o parte a actorilor economici cu care lucrau în mod tradițional ${ }^{33}$. Tehnologia sovietică uzată moral a fost înlocuită de cea produsă în Occident sau în statele Asiei de Sud, Rusia rămânând un simplu furnizor de materii prime. Și la acest capitol, economia sovietică a avut de suferit, din cauza pierderii controlului unor importanți furnizori energetici din statele Asiei Centrale. Inițial, producătorii de petrol și gaze naturale din Kazahstan, Turkmenistan și Uzbekistan depindeau de infrastructura de transport care se regăsea pe teritoriul rus. Acest lucru avantaja Federația Rusă, care putea stabili prețul de vânzare al acestor produse. $\mathrm{Cu}$ timpul, China, direct interesată de exploatarea gazelor și petrolului din acest spațiu, a investit sume considerabile și a creat un sistem de conducte care o conectau direct de câmpurile petrolifere din aceste state ${ }^{34}$.

Un alt semn de slăbiciune a Federației Ruse, în raport cu fostul său competitor din Războiul Rece, SUA, a fost pierderea unor avanposturi militare în teritorii considerate ca având importanță strategică pentru securitatea sa națională. Acest lucru nu s-a petrecut doar pe teritoriul statelor din Europa de Est, ci și pe teritoriul unora dintre fostele republici sovietice. Statele Baltice au fost primele entităţi care și-au exprimat dorința de a se desprinde politic și economic de spaţiul fostei URSS. În anul 2004, cele trei foste republici au aderat la NATO și la UE ${ }^{35}$, reușind, ulterior, să-și construiască un drum separat de Moscova. Mai puțin cunoscut publicului larg este faptul că slăbiciunea economică și militară manifestată de Rusia în anii '90 a permis Statelor Unite ale Americii să se apropie simțitor de zona petroliferă din jurul Mării Caspice. După destrămarea URSS, pentru o vreme fostele republici din Asia Centrală au continuat să graviteze în jurul Moscovei, de care continuau să depindă în privința importurilor tehnologice și infrastructurii de transport al principalelor produse exportate, petrolul și gazele naturale. Pe măsură ce li s-au creat condițiile necesare consolidării propriilor economii prin exporturi directe de gaze naturale și petrol, acestea au căutat noi oportunități de a se emancipa de sub tutela Moscovei.

După declanșarea războiul global împotriva terorismului în anul 2001, SUA și-au arătat disponibilitatea de a coopera cu acestea pentru a își dezvolta propria infrastructură energetică sau militară. În acest sens, guvernul SUA a aprobat mai multe împrumuturi către statele din Asia Centrală, Uzbekistanul primind 160 de milioane de dolari, iar Kirghizstanul, aproximativ 92 de milioane ${ }^{36}$. Acest gest nu era dezinteresat, guvernul american fiind interesat în acel moment să-și dezvolte o rețea de baze militare în jurul Afganistanului. SUA au negociat mai multe acorduri cu aceste state, prin care se dorea instalarea temporară a militarilor americani în baze aflate în proximitatea zonei de operaţii din Afganistan. În anul 2002, armata americană a desfășurat, în baza militară Karshi-Khanabad, din Uzbekistan, aproximativ 2.000 de soldaţi. Potrivit unui acord similar, Kirghizstanul a fost de acord să găzduiască până la 2.000 de militari la o bază aeriană, în localitatea Manas, în apropiere de capitala Biskek ${ }^{37}$, în vreme ce toate celelalte foste republici sovietice din zonă își exprimaseră acordul de a permite survolul aeronavelor militare americane.

Efectivele militare americane desfășurate în Afganistan și în statele vecine din proximitatea frontierei ruse au crescut rapid, de la aproximativ 25.000 de militari, în anul 2000, înainte de declanșarea războiului împotriva terorismului, la nu mai puțin de 80.000 , câțiva ani mai târziu ${ }^{38}$. Acest lucru a fost interpretat de autoritățile ruse ca o tentativă de încercuire a zonei petrolifere (prezența militară americană din zona Golfului Persic fusese instituită încă de la începutul anilor '90, în urma desfășurării conflictului împotriva Irakului), poziție din care SUA ar fi putut, ulterior, să lanseze un atac militar împotriva oricărui stat sau entitate nonstatală care i-ar fi putut pune în pericol interesele.

\section{Concluzii}

Instabilitatea politică din Rusia a luat sfârșit odată cu venirea la putere a fostului agent KGB VladimirPutin. Cuajutorul oamenilor din structurile de informații și ordine publică, acesta a restabilit controlul guvernului rus asupra tuturor regiunilor 
statului și asupra celor mai importante companii ale tării. Printr-o acțiune militară deosebit de violentă, Putin a reușit să pacifice zona Caucazului (a încheiat războiul din Cecenia) și a susținut direct mişcările separatiste din fostele republici sovietice. Bogatele resurse minerale la care statul rus avea acces au constituit un mare avantaj geopolitic. Prin intermediul acestora, a putut să pună presiune și să obțină concesii importante din partea statelor europene și a Chinei.

Redobândind, chiar și parţial, o parte a veniturilor sale, Rusia s-a lansat din nou într-o serie de acțiuni militare în afara teritoriului național, atât în cadrul fostului imperiu sovietic, cât și la mare distanţă de graniţele sale. Cele mai importante conflicte asumate total sau doar parțial de Moscova au fost cele din Siria și Ucraina. În anul 2014, Rusia s-a lansat în cea mai controversată acțiune politică din epoca postsovietică, invadând o parte din teritoriul vecinei sale Ucraina și anexând provincia Crimeea. Acest incident a contribuit semnificativ la suspendarea statului rus din forumul G8 $8^{39}$ și la impunerea unor sancțiuni economice din partea SUA și a principalelor state membre ale UE.

Acțiunile militare și politice întreprinse de această mare putere vor continua să atragă atenția factorilor de decizie din Occident și să îngrijoreze guvernele statelor vecine.

\section{NOTE:}

1 Blum Yehuda, "Russia Takes over the Soviet Union's Seat at the United Nations", European Journal of International Law, Volume 3, Issue 2, 1992, p. 354.

2 William Walker, "Nuclear Weapons and the Former Soviet Republics", International Affairs, Volume 68, Issue 2, April 1992, p. 256.

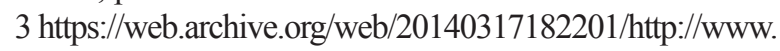
cfr.org/arms-control-disarmament-and-nonproliferation/ budapest-memorandums-security-assurances-1994/p32484\#, accesat la 28.02.2020.

4 Respectarea condițiilor prevăzute în cadrul memorandumului, semnat la Budapesta, pe care și-l asumaseră și Marea Britanie, China și Franța, a fost invocată de statul ucrainean, în momentul declanșării conflictului nedeclarat cu Federația Rusă, soldat cu pierderea Crimeii, în anul 2014. De asemenea, prevederile acestui tratat au fost reamintite comunității internaţionale și cu ocazia declanşării conflictului secesionist în partea de est a țării, unde statul ucrainean a acuzat din nou Rusia de amestec în problemele interne ale țării.

5 Constantin Hlihor, Politica de securitate în mediul internațional contemporan: domeniul energetic, Editura Institutul European, Iași, 2008, p. 103.

6 M. Luzhikova, Energy Security in Russia Federation, apud I. Chifu, A. Sauliuc, B. Nedea (ed.), Energy security strategies in the wider Black Sea Region, Editura Curtea Veche, București, 2010, p. 243.

7 Lars Petter Lundena, Daniel Fjaertofta, Indra Overland, Alesia Prachakova, "Gazprom vs. Other Russian gas producers: The evolution of the Russian gas sector", Energy Policy, No. 61, 2013, p. 663.

$8 \mathrm{https}: / /$ www.euractiv.com/section/politics/news/ hungarys-orban-defends-russia-cooperation-at-putinvisit/?fbclid=IwAR1Yc6W98EnP-e2h4j31stFLQsi_ntrCmA K80nAEBqY1J0_8QIBj96jKGPo, accesat la 29.02.2020.

9 Constantin Hlihor, op. cit., p. 131.

10 Sim Li-Chen, The Riseand Fall of Privatization in the Russian Oil Industry, Palgrave Macmillan, New York, 2008, p. 51.

11 Marshall Goldman, "Putin and the Oligarchs", Foreign Affairs, Vol. 83, No. 6, Nov. - Dec. 2004, p. 34, https:// www.jstor.org/stable/20034135, accesat la 26.06.2020.

12 Începând cu 24 martie 2014, Federaţia Rusă este suspendată din G8, ca urmare a agresiunii armate împotriva Ucrainei, soldată cu anexarea Peninsulei Crimeea. Smale Alison, Shear Michael, "Russia is oustead from group of 8 by US and Allies", The New York Times, March 24, 2014, https://www.nytimes.com/2014/03/25/world/europe/obamarussia-crimea.html, accesat la 26.06.2020.

13 Alexander Ghaleb, Natural gas as an instrument of Russia state power, US Army War College. Retrieved, 2011, p. 20, http://www.jstor.org/stable/resrep11537, accesat la 27.01.2021.

14 Rihard Morningstar, Andras Simonyi, Olga Khakova, Irina Markina, European Energy Diversification: How Alternative Sources, Routes, and Clean Technologies Can Bolster Energy Security and Decarbonization, Atlantic Council Global Energy Center, 2020, p. 2, https://www.jstor. org/stable/, accesat la 27.01.2021.

$15 \mathrm{https} / /$ ec.europa.eu/commission/presscorner/detail/ es/IP_19_1531, accesat la 27.01.2021.

16 Stefanova Boyka, "European Strategies for Energy Security in the Natural Gas Market", Journal of Strategic Security, Vol. 5, No. 3, Fall 2012, p. 58, https://www.jstor. org/stable/26463950, accesat la 28.01.2021.

17 Ibidem, p. 59.

18 David Matsaberidze, "Russia vs. EU/US through Georgia and Ukraine", Connections, Vol. 14, No. 2, Spring 2015, p. 82, https://www.jstor.org/stable/26326399, accesat la 28.01 .2021 .

19 http://www.nord-stream.com/en/the-pipeline/factsfigures.html, accesat la 28.01.2021.

20 Ibidem.

21 M. Luzhikova, op.cit., p. 259.

22 Ibidem.

23 George Mihailov, Rolul Turciei în securitatea energetică europeană, apud Dan Dungaciu, Darie Cristea (ed.), Doctrine, strategii, politici. De la discursul geopolitic la operaționalizarea securității internaționale, Editura Institutului de Ştiințe Politice și Relații Internaționale, București, 2012, p. 238.

24 Sergiu Tămaș, Geopolitica, Editura Institutului de Teorie Socială, București, 1999, p. 265.

25 Pretextul oficial al transferului îl reprezentase hotărârea poporului rus de a sărbători ,trei sute de ani de 
la reunificarea Ucrainei cu Rusia". De asemenea, fusese invocată și proximitatea geografică a acesteia față de Republica ucraineană, precum și legăturile economice care existau între aceste regiuni. Vezi Scânteia Nr. 2908, din 28 februarie 1954.

26 În anul 1997, președinții celor două state au semnat Acordul de prietenie dintre Ucraina și Federaţia Rusă, care reglementa această problemă. Înțelegerea a fost reînnoită, în anul 2010, de către președintele Medvedev, care a prelungit staţionarea pentru alți 25 de ani, în schimbul unor reduceri semnificative de preț pentru gazele rusești livrate Kievului.

27 Allison Roy, "Russian 'deniable' intervention in Ukraine: how and why Russia broke the rules", International Affairs, 90:6 , 2014, p. 1257.

28 Federația Rusă are deja graniță directă cu două state membre ale NATO (Polonia și Lituania) în zona enclavei Kaliningrad.

$29 \mathrm{https}: / /$ warontherocks.com/2015/06/the-budapest-mem orandum-and-the-russia-ukraine-crisis/, accesat la 28.02.2019.

$30 \mathrm{http}: / / w e b a r c h i v e . l o c . g o v / a l l / 20060720175013 /$ http://www.therussiasite.org/legal/laws/CISagreement.html, accesat la 28.01.2020

31 CSI a luat naștere la 8 decembrie 1991, prin semnarea acordului de la Belavezha. În cadrul acestui tratat, s-a decis ca, începând cu data de 26 decembrie 1991, URSS să înceteze să mai funcționeze ca stat.

32 Zbigniew $\mathrm{K}$ Brzezinski, Russia and the Commonwealth of Independent States: Documents, Data, and Analysis, Routledge, New York, 2015, p. 238, https:// books.google.ro/books?hl, accesat la 09.02.2021.

33 Robert Strayer, Why Did the Soviet Union Collapse? Understanding Historical Change, M.E. Sharpe, New York, 1998, p. 134, https://books.google.ro/books?hl, accesat la 09.02.2021.

34 În anul 2003, Kazahstanul, cu sprijinul economic și tehnologic al China, a reușit să inaugureze primii 448 de kilometri de conductă petrolieră, pe care Rusia nu îi mai controla în mod direct. În anul 2011, lungimea acestei conducte depăşise $2.798 \mathrm{~km}$, asigurând, pentru prima dată, independența totală, din punct de vedere economic, a statelor din Asia Centrală. Vezi Kazakhstan-China Crude Oil Pipeline, https://www.hydrocarbons-technology.com/projects/ kazakhstan-china-crude-oil-pipeline/, accesat la 26.06.2020.

35 Jurkynas Mindaugas, Security concerns of the Baltic States in thetwenty first century, p. 113, apud Clive Archer, Alyson J.K. Bailes, Anders Wivel, Small States and International Security: Europe and Beyond, Routledge, New York, 2014, https://books.google.ro/books?, accesat la 11.02.2021.

36 Paul Dobrescu, Geopolitica, Editura Comunicare.ro, București, 2003, p. 312.

37 Douglas Schorzman, "Staging Base for Afghan War Handed Over to Kyrgyzstan", The New York Times, June 2, 2014, https:/www.nytimes.com/2014/06/04/world/asia/stag ing-base-for-afghan-war-is-handed-to-kyrgyzstan.html, accesat la 26.06.2020.

38 Paul Dobrescu, op.cit., p. 311.

39 Alison Smale, Michael Shear, "Russia Is Ousted From Group of 8 by US and Allies", New York Times, March 24 2014, https://www.nytimes.com/2014/03/25/world/europe/ obama-russia-crimea.html, accesat la 05.10.2020.

\section{BIBLIOGRAFIE}

Archer Clive, Bailes J.K. Alyson, Wivel Anders, Small States and International Security: Europe and Beyond, Routledge, New York, 2014.

Blum Yehuda, "Russia Takes over the Soviet Union's Seat at the United Nations", European Journal of International Law, Volume 3, Issue 2, 1992.

Boyka Stefanova, "European Strategies for Energy Security in the Natural Gas Market", Journal of Strategic Security, Vol. 5, No. 3, Fall 2012.

Chifu I., Sauliuc A., Nedea B. (ed.), Energy security strategies in the wider Black Sea Region, Editura Curtea Veche, București, 2010.

Dobrescu Paul, Geopolitica, Editura Comunicare.ro, București, 2003.

Dungaciu Dan, Cristea Darie (ed.), Doctrine, strategii, politici. De la discursul geopolitic la operaționalizarea securității internaționale, Editura Institutului de Ştiințe Politice și Relații Internaționale, București, 2012.

Ghaleb Alexander, Natural gas as an instrument of Russia state power, US Army War College. Retrieved, 2011.

Goldman Marshall, "Putin and the Oligarchs", Foreign Affairs, Vol. 83, No. 6, Nov. - Dec. 2004.

Hlihor Constantin, Politica de securitate în mediul internațional contemporan: domeniul energetic, Editura Institutul European, Iași, 2008.

Lars Petter Lundena, Fjaertofta Daniel, Overland Indra, Prachakova Alesia, "Gazprom vs. Other Russian gas producers: The evolution of the Russian gas sector", Energy Policy, No. 61, 2013.

Matsaberidze David, "Russia vs. EU/US through Georgia and Ukraine", Connections, Vol. 14, No. 2, Spring 2015.

Morningstar Rihard, Simonyi Andras, Khakova Olga, Markina Irina, European Energy Diversification: How Alternative Sources, Routes, and Clean Technologies Can Bolster Energy Security and Decarbonization, Atlantic Council Global Energy Center, 2020.

Roy Allison, 'Russian 'deniable' intervention in Ukraine: how and why Russia broke the rules", International Affairs, 90: 6, 2014.

Schorzman Douglas, Staging Base for Afghan War Handed Over to Kyrgyzstan, The New York Times, June 2, 2014. 
Sim Li-Chen, The Rise and Fall of Privatization in the Russian Oil Industry, Palgrave Macmillan, New York, 2008.

Smale Alison, Shear Michael, "Russia Is Ousted From Group of 8 by US and Allies", New York Times, March 24, 2014.

Strayer Robert, Why Did the Soviet Union Collapse? Understanding Historical Change, M.E. Sharpe, New York, 1998.

Tămaș Sergiu, Geopolitica, Editura Institutului de Teorie Socială, București, 1999.

Walker William, "Nuclear Weapons and the Former Soviet Republics", International Affairs, Volume 68, Issue 2, April 1992.

Zbigniew K. Brzezinski, Russia and the Commonwealth of Independent States: Documents, Data, and Analysis, Routledge, New York, 2015. https:/www.hydrocarbons-technology.com/ projects/kazakhstan-china-crude-oil-pipeline https://warontherocks.com/2015/06/the-buda pest-memorandum-and-the-russia-ukraine-crisis/ http://webarchive.loc.gov/all/20060720175013/ http://www.therussiasite.org/legal/laws/CISagree ment.html

http://www.nord-stream.com/en/the-pipeline/ facts-figures.html

https://ec.europa.eu/commission/presscorner/ detail/es/IP_19_1531

https://www.nytimes.com/2014/03/25/world/ europe/obama-russia-crimea.html,

https://web.archive.org/web/20140317182201/ http://www.cfr.org/arms-control-disarmamentand-nonproliferation/budapest-memorandumssecurity-assurances-1994/p32484\#,

https://www.euractiv.com/section/politics/ news/hungarys-orban-defends-russia-cooperationat-putin-visit/?fbclid=Iw AR1 Yc6W98EnPe2h4j31stFLQsi_ntrCmAK80nAEBqY1J0_ 8QIBj96jKGPo

https://warontherocks.com/2015/06/thebudapest-memorandum-and-the-russia-ukrainecrisis/ 